\title{
Blunted DNA synthesis and delayed S-phase entry following inhibition of Cdk2 activity in the regenerating rat liver
}

\author{
Peter Stärkel $^{1}$, Christine De Saeger ${ }^{1}$, Christine Sempoux ${ }^{2}$, Eric Legrand ${ }^{3}$, Isabelle Leclercq \\ and Yves Horsmans ${ }^{1}$ \\ ${ }^{1}$ Laboratory of Gastroenterology, Université Catholique de Louvain, Brussels, Belgium; ${ }^{2}$ Laboratory of \\ Pathology, Université Catholique de Louvain, Brussels, Belgium and ${ }^{3}$ Laboratory of Experimental Surgery, \\ Université Catholique de Louvain, Brussels, Belgium
}

\begin{abstract}
Activation of the cyclin E/Cdk2 complex may play an important role in mid-G1/S-phase progression in proliferating mammalian cells. We evaluated the effect of targeted inhibition of Cdk2 activity by CYC202 (Rroscovitine) on hepatocytes proliferation in vivo after $70 \%$ partial hepatectomy $(\mathrm{PH})$ in rats. In controls, Cdk2 activity and DNA synthesis peaked $24 \mathrm{~h}$ after PH. CYC202 abrogated Cdk2 activity, prevented BrdU incorporation and PCNA expression and increased mortality $24 \mathrm{~h}$ after PH. Cyclin E and Cdk2 protein expression and complex formation was not affected by CYC202 nor was cyclin D1, Cdk4 and c-ras mRNA expression. Two consecutive injections 8 and $20 \mathrm{~h}$ after PH were required to elicit the inhibitory effect of CYC202, which was lost when either the injection at $8 \mathrm{~h}$ or at $20 \mathrm{~h}$ was withheld. Cdk2 activity and cell progression resumed $48 \mathrm{~h}$ after $\mathrm{PH}$ in surviving animals suggesting that CYC202 induced a reversible inhibition of the cell cycle. Our results confirm an important role for Cdk2 in hepatocytes proliferation in the regenerating liver. We demonstrate that molecular events, including Cdk2 activation, occurring within the 8th and 24th hour after PH (G1/S-phase transition) are crucial in determining whether or not DNA synthesis and hepatocytes proliferation proceed normally after $\mathrm{PH}$.
\end{abstract}

Laboratory Investigation (2005) 85, 562-571, advance online publication, 31 January 2005; doi:10.1038/labinvest.3700245

Keywords: liver regeneration; cyclins; cyclin-dependent kinases; cell cycle; roscovitine

Adult quiescent hepatocytes retain the almost unrestricted ability to resume cell cycle in response to acute liver injury or liver resection. Therefore, the partial hepatectomy model constitutes an ideal tool to study the significance of cell cycle events and cell-cycle-related proteins in mammalian cells in vivo. In rats, hepatocytes enter the G1 phase of the cell cycle almost immediately after partial hepatectomy in order to restore the initial liver mass. A peak of DNA synthesis is observed at $24 \mathrm{~h}$ and mitosis occurs from the 30th hour onwards. ${ }^{1,2}$ This process requires a tight coordination of several pathways including activation of specific cyclin/ cylin-dependent kinase (Cdk) complexes at different intervals during the cell cycle. Cyclin D1/Cdk4 or Cdk6 are activated in mid-G1, while cyclin E/Cdk2

Correspondence: Dr P Stärkel, MD, PhD, Department of Gastroenterology, St Luc University Hospital, Av. Hippocrate 10, 1200 Brussels, Belgium.

E-mail: peter.starkel@gaen.ucl.ac.be

Received 21 September 2004; revised 6 December 2004; accepted 7 December 2004; published online 31 January 2005 controls G1/S phase transition. Progression of DNA synthesis is assured by cyclin A/Cdk2. ${ }^{3-5}$ Several studies found an induction of cyclin $\mathrm{E}$ and $\mathrm{Cdk} 2$ at time points near the G1/S boundary in the regenerating rat hepatocytes. ${ }^{6-9}$ Furthermore, a subcellular rearrangement of cyclins and Cdks is observed in the remnant liver with cyclin E and Cdk2 moving from the cytosol into the nucleus. ${ }^{6}$ The cyclin E/Cdk2 complex acts as a histone $\mathrm{H} 1$ kinase and the peak of its activity closely correlates with the peak of DNA synthesis in the regenerating hepatocytes. ${ }^{6,10}$ Cyclin $\mathrm{E}$ and Cdk2 induction, redistribution and activity have been shown to be disturbed in several models of impaired liver regeneration. ${ }^{11-13}$ In addition, hepatocyte proliferation can be stimulated by targeted modulation of cyclin E. ${ }^{14}$ Although, these data suggest that cyclin $\mathrm{E}$ and Cdk2 might be important in orchestrating the cell cycle in the regenerating liver, the exact role of the active cyclinE/Cdk2 complex remains to be defined.

Over the last few years, protein kinase inhibitors have gained considerable interest as targets for treatment of a number of diseases. A series of small 
compounds acting as chemical inhibitors of Cdks activity have been characterized. Among those, roscovitine discloses a high selectivity for Cdk2 blocking its activity presumably by competing with ATP for binding at the catalytic site. ${ }^{15-17}$ Studies with a chemically pure form of R-roscovitine have shown that it acts as a potent inhibitor of cyclinE/ Cdk2 kinase activity with selectivity for rapidly proliferating cells resulting in reduced tumor cell proliferation in vitro and in vivo. ${ }^{18}$ Consequently, the compound is currently tested in phase II clinical trials for advanced breast cancer and non-small-cell lung cancer. ${ }^{17}$ In our study, we used this chemically pure form of R-roscovitine to investigate the impact of targeted inhibition of the Cdk2 activity on hepatocytes proliferation after partial hepatectomy.

\section{Materials and methods}

\section{Animals}

Male Wistar rats (220-270g body weight) were obtained from the Rat Breeding Facilities of the Catholic University of Louvain Medical School, Brussels, Belgium. All animals were kept in a temperature- and humidity-controlled environment in a 12-h light-dark cycle. They were allowed free access to water and standard food pellet diet (Usine d'Alimentation Rationelle, Villemoisson-sur-Orges, France). The animals were handled according to the guidelines established by the Catholic University of Louvain.

\section{Surgical Procedures and Experimental Design}

All operations were carried out under light ether anesthesia at room air between 0900 and 1200 with use of a clean but not sterile technique. Partial hepatectomy $(\mathrm{PH})$ was performed according to Higgins and Anderson. ${ }^{19}$ Animals were weighted immediately before $\mathrm{PH}$, before each injection after $\mathrm{PH}$ and immediately before killing. The animals were killed by exsanguination after puncture of the abdominal aorta and transection of the inferior vena cava in the thoracic cavity at 16, 24 or $48 \mathrm{~h}$ after PH. The livers were removed, rapidly weighted, snap frozen in liquid nitrogen and stored at $-80^{\circ} \mathrm{C}$. A small piece of liver was immersed in a $4 \%$ buffered formaldehyde for histological and immunohistochemical analysis. The body weight before $\mathrm{PH}$ and the weight of the regenerating liver at killing were used to estimate the body weight to liver weight ratio. At least three rats were used for each experiment and time point. Control animals were injected with dimethyl sulfoxide (DMSO) only. In the treatment groups, CYC202 (R-roscovitine) (generous gift from Cyclacel Ltd, Dundee, UK) dissolved in DMSO was injected intraperitoneally (6 or $75 \mathrm{mg} / \mathrm{kg}$ ) at various time points before and/or after $\mathrm{PH}$. These dosages were based on the information obtained from the supplier Cyclacel indicating that repeat oral doses of 50 to $100 \mathrm{mg} / \mathrm{kg}$ and repeat intraperitoneal doses of $7 \mathrm{mg} / \mathrm{kg}$ were well tolerated in rats. Experiments were also repeated with CYC202 $50 \mathrm{mg} / \mathrm{kg}$ in order to demonstrate the dose-dependent effect of the molecule. The following injection schemes have been used: $16 \mathrm{~h}$ before $\mathrm{PH}$ followed by repeated injections 1 and $8 \mathrm{~h}$ or 1,8 , and $20 \mathrm{~h}$ after $\mathrm{PH}$, repeated injections at 8 and $20 \mathrm{~h}, 8$ and $16 \mathrm{~h}, 12$ and $16 \mathrm{~h}$ or a single injection at $20 \mathrm{~h}$ after $\mathrm{PH}$.

\section{Preparation of Cell Fractions}

Cell lysates and nuclear extracts were prepared from the frozen liver using the nuclear extract kit (Active Motif, Rixensart, Belgium) following the instructions of the manufacturer. Protein contents were determined using a BCA Protein Assay with serum albumin as a standard (Pierce Chemical, Rockford, IL, USA).

\section{RNA Isolation, Reverse Transcription and Real-Time Polymerase Chain Reaction}

Total RNA was prepared from the frozen liver tissue using TriPure Isolation Reagent (Roche Diagnostics, Indianapolis, IN, USA) following the instructions of the manufacturer. Reverse transcription and quantitative polymerase chain reaction (PCR) analysis was carried out as previously described by our group. ${ }^{20}$ The following primers were used: ras; sense agcataaactgcggaaactgaac, antisense catgagctgcaagtgt gtgct, RPL19; sense caagcggattctcatggaaca, antisense tggtcagccaggagcttctt.

\section{Western Blotting, Immunoprecipitation and Cdk2 Kinase Assay}

Westen blotting, immunoprecipitation and histone H1 kinase assay (Cdk2 activity) were performed as previously described. ${ }^{10}$ The following antibodies were used: cyclin E, Cdk4, Cdk2 rabbit polyclonal, cyclin D1 mouse monoclonal (all Santa Cruz Biotechnology, Santa Cruz, CA, USA), proliferating cell nuclear antigen (PCNA) mouse monocloanal (Dako, Glostrup, Denmark), $\beta$-actin mouse monoclonal (Sigma, St Louis, MI, USA) primary and peroxidase-conjugated goat anti-mouse and mouse anti-rabbit (Jackson ImmunoResearch, West Grove, PA, USA) secondary antibodies. Membranes were stripped using Restore Western blot stripping buffer (Pierce Chemical) following the instructions of the manufacturer and reprobed with different antibodies whenever possible. The amount of immunoreactive nuclear protein on each membrane was quantified using an UltroScan XL device (Pharmacia LKB). The optical density units per surface (OD/ $\mathrm{mm}^{2}$ ) were adjusted for total protein load ( $\beta$-actin). 


\section{Histology and Immunohistochemistry}

Formalin-fixed paraffin-embedded sections were stained with hematoxylin-eosin (liver, kidney, intestine) and the mitotic index in the liver was determined as follows: three to five high-power fields were counted per rat. Each field was divided into three zones, zone 1 being closest to the centrolobular vein and zone 3 corresponding to the periportal area. The mitotic index expressed in percentage was defined as the ratio between the number of mitosis and the total number of counted hepatocytes (1500 cells per animal). All sections were analyzed by the same experienced liver pathologist (CS).

Immunohistochemical staining for bromodeoxyuridine (BrdU) on hepatic paraffin sections was performed as described by Picard et al. ${ }^{21}$

\section{Flow Cytometry}

Incorporation of BrdU into DNA was quantified by flow cytometry (fluorescence-activated cell sorter, FACS) essentially as described by Borbath et al. ${ }^{22}$

\section{Caspase 3 Activity Assay}

Caspase 3 activity was assessed in liver homogenates as described by our group ${ }^{23}$ using the fluorogenic substrate Ac-DEVD-AFC (Alexis Biochemicals, Lausen, Switzerland), which is cleaved enzymatically by caspase 3 , releasing free AFC which produces a blue-green fluorescence.

\section{Statistical Analysis}

Results are expressed as means \pm standard error of the mean (s.e.m.). The statistical differences between the groups were tested using the Student's $t$-test. Statistical significance was admitted for a $P$-value $<0.05$.

\section{Results}

\section{Administration of CYC202 during Mid-G1/S-Phase Progression Inhibits Cdk2 Activity in the Regenerating Rat Liver}

In order to determine whether CYC202 inhibits Cdk2 in vivo a histone $\mathrm{H} 1$ kinase assay was performed following repeated injections of CYC202 at various time points before and after $\mathrm{PH}$. Cdk2 activity was absent in quiescent liver. In control (DMSO-treated) animals, a marked increase in Cdk2 activity was present $16 \mathrm{~h}$ post-PH and peaked $24 \mathrm{~h}$ after PH. Cdk2 activity also occurred normally at the 16th and 24th hour after PH in animals that were repeatedly injected a high dose of CYC202 $(75 \mathrm{mg} / \mathrm{kg}) 16 \mathrm{~h}$ prior and 1 and $8 \mathrm{~h}$ after $\mathrm{PH}$. By contrast, when an additional injection of CYC202

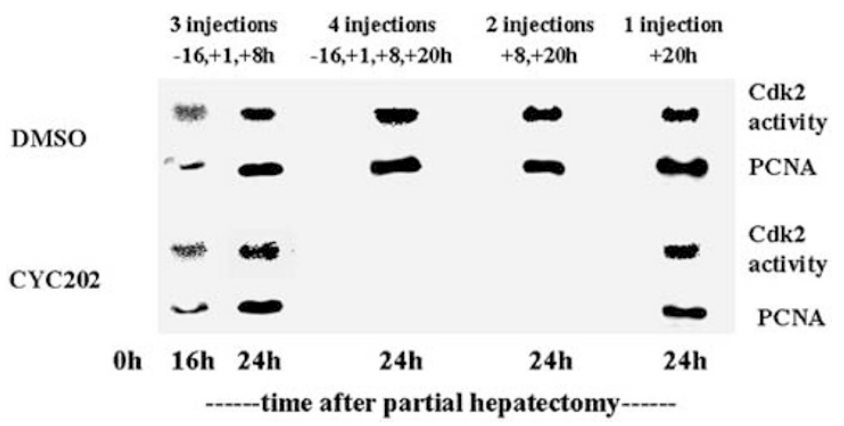

Figure 1 Immunoprecipitation of nuclear Cdk2 followed by the histone H1 kinase assay and the corresponding Western blot of PCNA expression in cell lysates before partial hepatectomy (PH) $(0 \mathrm{~h})$ and 16 and $24 \mathrm{~h}$ after $\mathrm{PH}$ in DMSO-treated rats (upper part) and in animals administered the Cdk2 inhibitor (CYC202, $75 \mathrm{mg}$ / $\mathrm{kg}$, lower part). Two injections of CYC202 at 8 and $20 \mathrm{~h}$ after $\mathrm{PH}$ were sufficient to completely block Cdk2 kinase activity. In parallel, PCNA expression was absent in animals that showed inhibition of Cdk2 activity. The inhibitory effect of CYC202 was lost when the treatment comprised only three injections, $16 \mathrm{~h}$ before and 1 and $8 \mathrm{~h}$ after $\mathrm{PH}$ or when 1 single injection was given $20 \mathrm{~h}$ after $\mathrm{PH}$. The results are representative of at least three independent experiments with three animals in the DMSO and five animals in the CYC202 group.

was administered at the 20th hour after PH (injections $16 \mathrm{~h}$ prior and 1,8 , and $20 \mathrm{~h}$ after $\mathrm{PH})$, a complete block of both cytoplasmic (not shown) and nuclear Cdk2 activity was observed $24 \mathrm{~h}$ after $\mathrm{PH}$ (Figure 1). The effect of CYC202 on Cdk2 activity was lost when the animals were repeatedly injected a low dose of CYC202 $(6 \mathrm{mg} / \mathrm{kg})$, and injections of CYC202 at a dose of $50 \mathrm{mg} / \mathrm{kg}$ produced only a very minor inhibitory effect on Cdk2 activity (not shown). These observations suggest a dose-dependent effect of CYC202 as well as an important role for the 20th hour time point after PH.

We next investigated whether it is necessary to inject the inhibitor before the 8th hour after $\mathrm{PH}$. Indeed, two injections of CYC202 at 8 and $20 \mathrm{~h}$ after $\mathrm{PH}$ were sufficient to abrogate completely Cdk2 activity at $24 \mathrm{~h}$ after $\mathrm{PH}$ (Figure 1). However, no Cdk2 inhibition was observed when only a single injection at $20 \mathrm{~h}$ after $\mathrm{PH}$ was given confirming that both injections at 8 and $20 \mathrm{~h}$ after $\mathrm{PH}$ are required for blocking Cdk2 activity. We then tested whether injections of CYC202 at other time points within the 8-20 h time interval would produce a similar inhibitory effect. Administration of the compound at 8 and $16 \mathrm{~h}$ or at 12 and $16 \mathrm{~h}$ after $\mathrm{PH}$ did reduce but not completely block Cdk2 activity as observed with two injections at 8 and $20 \mathrm{~h}$ (not shown). These results suggest that an optimal inhibitory effect is achieved by two injections of high-dose CYC202 $(75 \mathrm{mg} / \mathrm{kg})$ at 8 and $20 \mathrm{~h}$ after $\mathrm{PH}$, a time period corresponding to mid-G1/S-phase progression and early S-phase entry in the regenerating rat hepatocyte. ${ }^{1,2,24}$ Based on these results, all further analysis were carried out in animals having received two injections of either DMSO or CYC202 at 8 and $20 \mathrm{~h}$ after $\mathrm{PH}$. 
Inhibition of Cdk2 Activity Delays Cell Cycle Progression and Liver Cell Proliferation after PH

The peak of DNA synthesis in the regenerating rat liver is located around the 24th hours after PH. We therefore studied cell cycle progression and DNA synthesis by assessing PCNA expression and BrdU incorporation 16, 24 and $48 \mathrm{~h}$ after PH. In DMSOtreated animals as well as in the low-dose regimen of CYC202 (6 mg/kg) (not shown), PH was associated with an induction of PCNA and an increased number of BrdU-positive hepatocytes peaking as expected at $24 \mathrm{~h}$. By contrast, with the high-dose regimen of CYC202 $(75 \mathrm{mg} / \mathrm{kg}) \mathrm{PH}$ did neither induce PCNA expression nor stimulate DNA synthesis $24 \mathrm{~h}$ after $\mathrm{PH}$ (Figures 1 and 2) paralleling the inhibition of Cdk2 activity. In addition, DMSOtreated rats already showed mitotic figures principally located around the portal tract at $24 \mathrm{~h}$ after $\mathrm{PH}$ whereas no mitotic figures were found in rats administered the high-dose regimen of CYC202 (Figure 3). In parallel to the inhibition of cell cycle progression, there was a nonsignificant trend towards lower liver weights in CYC202-treated animals at $24 \mathrm{~h}$ after $\mathrm{PH}$ (Figure $4 \mathrm{a}$ ). In addition, the ratio of liver weight to body weight at killing (Figure 4b) as well as the ratio of liver weight to the initial body weight was lower in CYC202-treated animals with complete inhibition of Cdk2 activity $(n=8)$ compared to DMSO-treated rats $(n=9)$ (ratio: $1.5 \pm 0.06 \%$ vs $1.69 \pm 0.07 \%, P=0.07$, respectively) suggesting a decreased liver weight recovery at $24 \mathrm{~h}$ after PH. These observations confirm that the presence of the Cdk inhibitor CYC202 between 8 and $20 \mathrm{~h}$, a time corresponding to G1/S transition and S-phase entry, abrogates hepatocyte proliferation $24 \mathrm{~h}$ after $\mathrm{PH}$.

Furthermore, in rats treated with a Cdk2 inhibitory regimen of CYC202 $(75 \mathrm{mg} / \mathrm{kg})$ mortality rate at $24 \mathrm{~h}$ post-PH was about $25 \%$ (five out of 19) and increased to $50 \%$ at $48 \mathrm{~h}$ after $\mathrm{PH}$ (five out of 10 ). Most of the deaths occurred beyond the 20th hour after $\mathrm{PH}$ except for two animals that died between the 8th and the 20th hour. By contrast, there was no mortality up to $48 \mathrm{~h}$ post-PH in control rats receiving
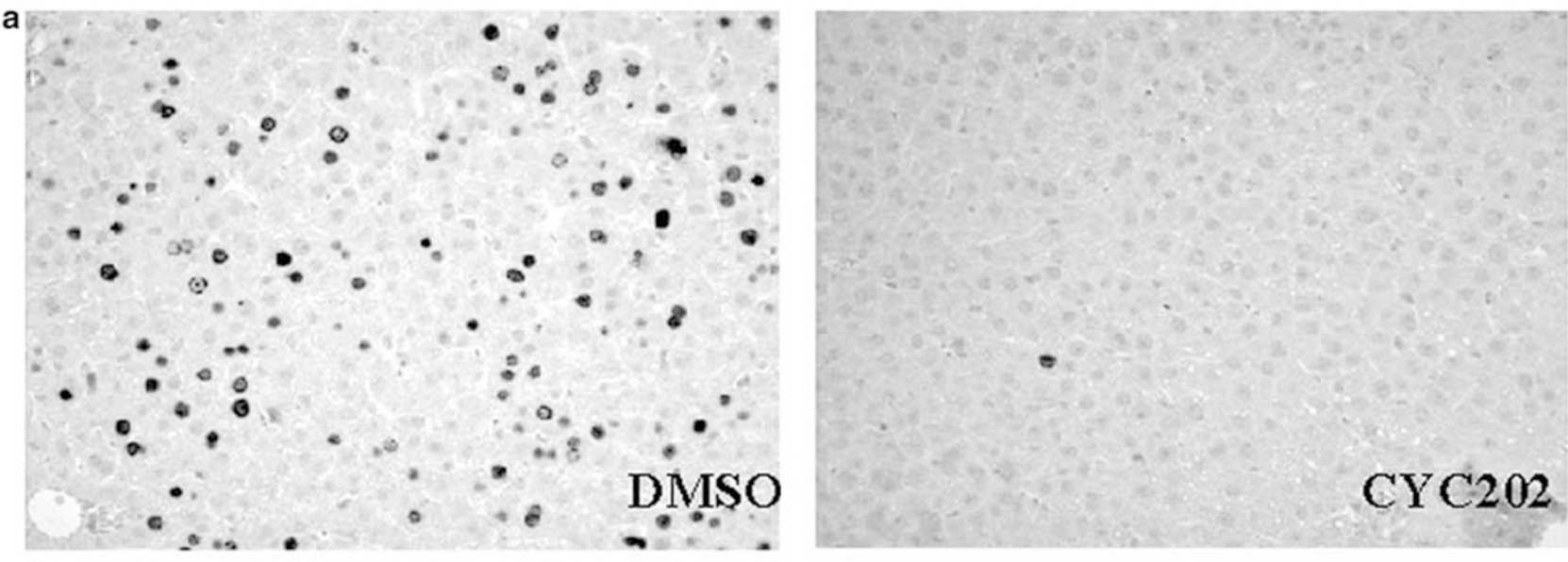

b

BrdU incorporation

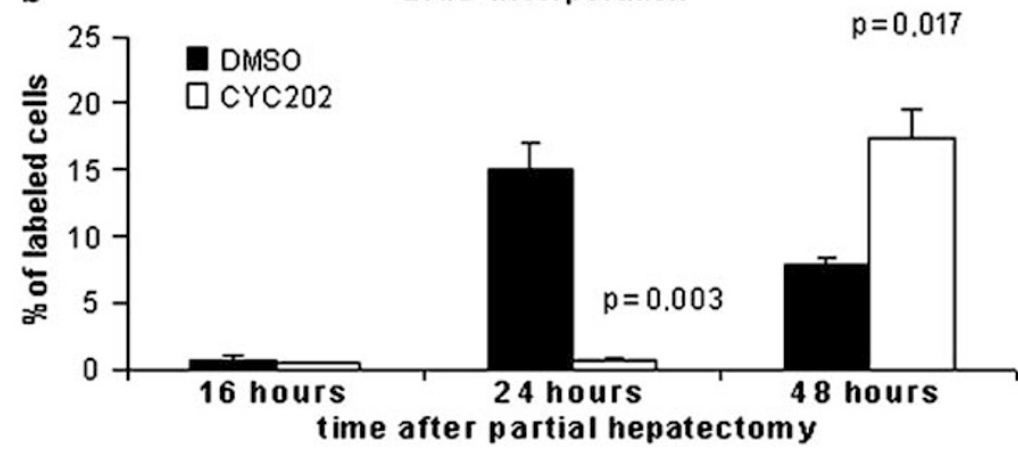

Figure 2 (a) Representative immunohistochemisty of BrdU incorporated into hepatocyte nuclei $24 \mathrm{~h}$ after partial hepatectomy (PH) in rats treated with DMSO or the Cdk2 inhibitor (CYC202, $75 \mathrm{mg} / \mathrm{kg}$ ). BrdU incorporation was preserved in DMSO-treated animals whereas no BrdU incorporation was found in rats in which Cdk2 kinase activity was completely inhibited by two injections of CYC202 8 and $20 \mathrm{~h}$ after PH. The BrdU staining is respresentative for three animals in the DMSO and five animals in the CYC202 group. (b) BrdU labeling index determined by flow cytometry (mean \pm s.e.m.) in animals $(n=3$ to 5 per group) administered DMSO only or an inhibitory regimen (two injections 8 and $20 \mathrm{~h}$ after PH) of the Cdk2 inhibitor (CYC202, $75 \mathrm{mg} / \mathrm{kg}$ ). Surviving rats were killed at 16, 24 or $48 \mathrm{~h}$ after PH. DNA synthesis was delayed by several hours in animals that survived the CYC202 treatment whereas the peak of DNA synthesis occurred normally in DMSO-injected animals at $24 \mathrm{~h}$ after PH. $P$-values on the top of the columns compare CYC202-treated survivors to their respective DMSO-treated group at the same time point. 

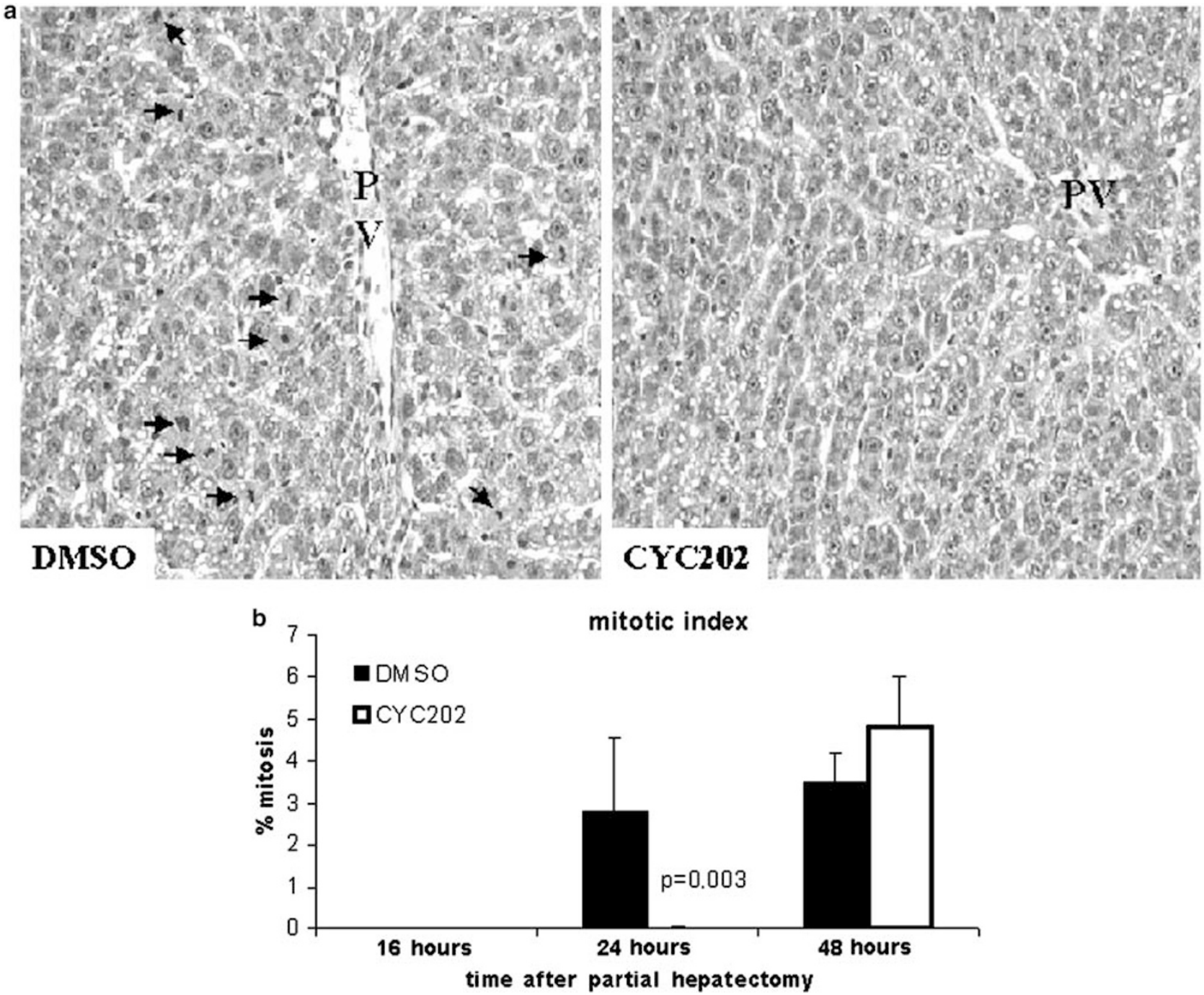

Figure 3 (a) Representative histology (hematoxylin and eosin) $24 \mathrm{~h}$ after partial hepatectomy (PH) in DMSO-treated animals and in rats administered two inhibitory injections of the Cdk2 inhibitor (CYC202, $75 \mathrm{mg} / \mathrm{kg}$ ) 8 and $20 \mathrm{~h}$ after PH. Numerous mitotic figures (arrows) were found principally around the portal tract (PV) in DMSO-treated rats whereas hardly any mitotic figures were seen in CYC202 animals in which Cdk2 kinase activity was completely blocked. The hematoxylin and eosin staining is respresentative for three animals in the DMSO and five animals in the CYC202 group. (b) Mitotic index 16, 24 and $48 \mathrm{~h}$ after PH in DMSO-treated animals and surviving animals ( $n=3-5$ per group) administered an inhibitory regimen of CYC202 (two injections 8 and $20 \mathrm{~h}$ after PH). In parallel to the delay in DNA synthesis, mitotic activity was retarded by several hours in surviving animals administered CYC202. $P$-values on the top of the columns compare CYC202-treated survivors to their respective DMSO-treated group at the same time point.

DMSO injections or in rats administered the lowdose $(6 \mathrm{mg} / \mathrm{kg})$ or non-Cdk2 inhibitory regimens of CYC202.

Since the low-dose regimen of CYC202 $(6 \mathrm{mg} / \mathrm{kg})$ did neither inhibit Cdk2 activity nor influence mortality or markers associated with progression to $S$ phase, all further analysis was only carried out in DMSO-treated rats and animals that received the high-dose regimen of CYC202 $(75 \mathrm{mg} / \mathrm{kg})$.

\section{Cyclin E and Cdk2 Nuclear Redistribution and Upregulation is not Altered by CYC202}

We investigated whether the inhibition of S-phase entry and DNA synthesis could be explained by reduced levels of cyclin E or Cdk2. In vitro data in mammalian cells suggest that nuclear but not cytosolic cyclin E and Cdk2 are required for initiation of DNA synthesis. ${ }^{25,26}$ We therefore concentrated our analysis mainly on nuclear expression of both proteins. No major changes of both proteins were found in the cytosol (not shown). By contrast, nuclear redistribution and upregulation of cyclin $\mathrm{E}$ and Cdk2 occurred equally in CYC202 and DMSOtreated animals (Figure 5a). Quantification of both proteins by densitometry at 16 and $24 \mathrm{~h}$ after $\mathrm{PH}$ showed a similar upregulation in the treatment and in the control groups suggesting that CYC202 does inhibit the activity of Cdk2 without significantly affecting expression of the protein components of the cyclin E/Cdk2 complex (Figure 6). Since cyclin E 
a
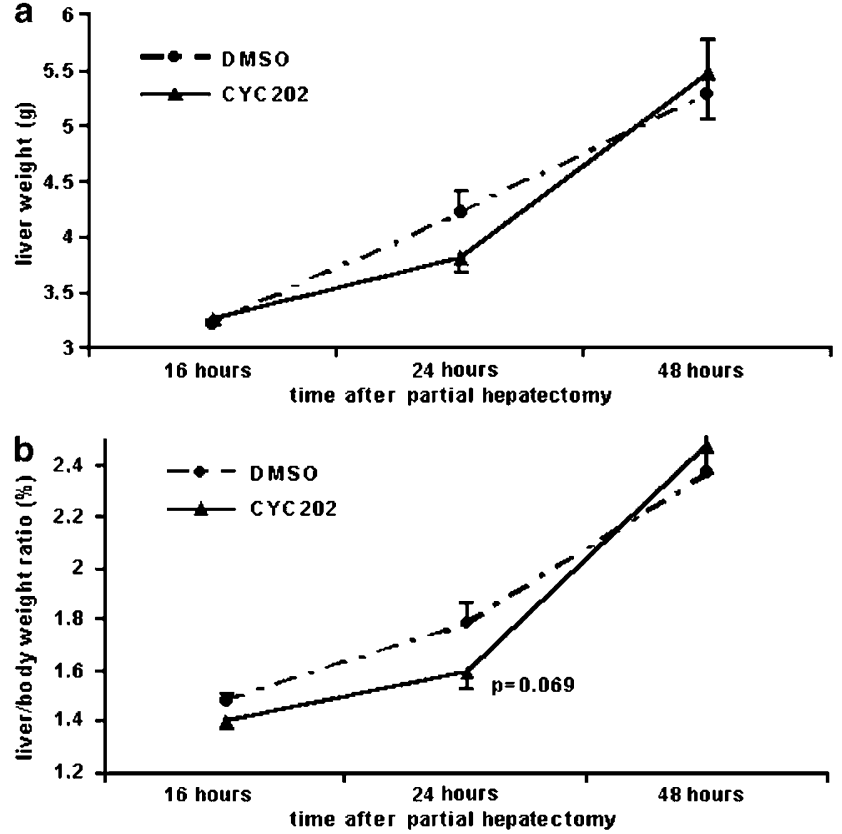

Figure 4 Evolution of liver weights (a) and liver to body weight ratio at killing (b) at various time points after partial hepatectomy $(\mathrm{PH})$ in DMSO-treated rats and in animals treated with an inhibitory regimen (two injections 8 and $20 \mathrm{~h}$ after $\mathrm{PH}$ ) of the Cdk2 inhibitor (CYC202, $75 \mathrm{mg} / \mathrm{kg}$ ). Means \pm s.e.m. are represented. Three to five animals per time point and per treatment group were analyzed. In parallel to Cdk2 inhibition, livers were smaller and the liver to body weight ratio was lower in CYC202treated animals $24 \mathrm{~h}$ after $\mathrm{PH}$.

and Cdk2 expression did not seem to be affected by CYC202, we assessed whether CYC202 treatment might result in deficient cyclin E/Cdk2 complex formation leading to inhibition of Cdk2 activity. Immunoprecipitation of liver homogenates with an anti-cyclin E antibody followed by Western blot analysis of the precipitates with an anti-Cdk2 antibody did not show any significant differences in cyclin E/Cdk2 complex formation between animals treated with DMSO or with CYC202, respectively (Figure 5b).

\section{CYC202 does not Interfere with Mid-G1 Events of the Cell Cycle}

Since cyclin D1 and Cdk4 increase in the regenerating liver from mid-G1 phase onwards, we were prompted to assess the expression of both proteins in our experimental setting. Only minor variations of both proteins were found in the cytosol (not shown). By contrast, nuclear redistribution and upregulation of the cyclin D1 protein occurred equally at 16 and $24 \mathrm{~h}$ after $\mathrm{PH}$ in CYC202- and DMSO-treated animals (Figures 5 and 6). As with cyclin D1, nuclear Cdk4 increased similarly in both, the CYC202-treated and the control rats at 16 and $24 \mathrm{~h}$ after $\mathrm{PH}$ (Figures 5 and 6). At $24 \mathrm{~h}$ after $\mathrm{PH}$, nuclear Cdk4 levels were even higher in animal treated with CYC202 but the difference did not reach statistical significance. Time after $\mathrm{PH}$ 0h 16h 24h 16h 24h

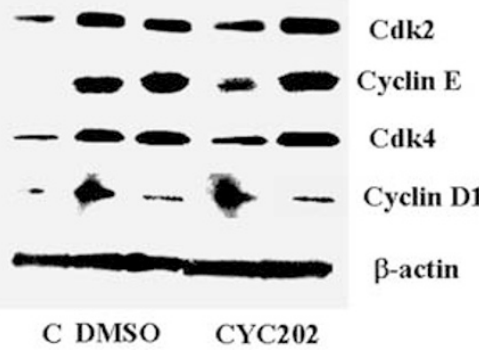

b IP:

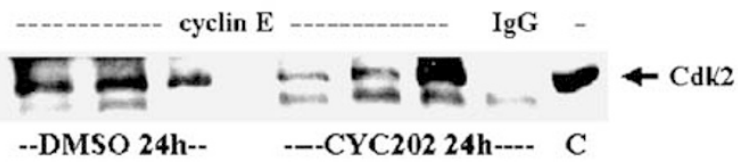

Figure 5 (a) Representative Western blots of cell cycle proteins in nuclear extracts before $(0 \mathrm{~h})$ and 16 and $24 \mathrm{~h}$ after partial hepatectomy $(\mathrm{PH})$ in DMSO-treated rats and in animals treated with an inhibitory regimen (two injections 8 and $20 \mathrm{~h}$ after $\mathrm{PH}$ ) of the Cdk2 inhibitor (CYC202, $75 \mathrm{mg} / \mathrm{kg}$ ). $\beta$-Actin blots represent loading controls. All Western blots have been produced in duplicate. The blots are representative for three to five animals per time point and per treatment group. (b) Immunoprecipitation of liver nuclear extracts prepared from individual animals $24 \mathrm{~h}$ after $\mathrm{PH}$ with an anti-cyclin E antibody followed by Western blot of the precipitates with an anti-Cdk2 antibody in DMSO-treated rats $(n=3$, first block of three lanes labeled DMSO) or in animals administered an inhibitory regimen of CYC202 $(n=3$, second block of three lanes labeled CYC202). Replacement of the anticyclin E antibody by a species related non-specific immunoglobulin was used as a negative control. A rat nuclear extract of an untreated animal obtained $24 \mathrm{~h}$ after $\mathrm{PH}$ served as a positive control (c, last lane). No significant differences in cyclin E/Cdk2 complex formation was found between DMSO- and CYC202treated animals.

Expression of ras proto-oncogenes is induced in the regenerating rat liver in mid/late G1 phase and peak levels are reached at $24 \mathrm{~h}$ after $\mathrm{PH} .^{1,2}$ It might therefore serve as an additional marker of G1/Sphase progression. Furthermore, a relationship between ras expression and cyclin E/Cdk2 seems to exist in regenerating hepatocytes. ${ }^{13}$ In our experimental setting, determination of ras mRNA levels by quantitative PCR revealed a similar increase of the proto-oncogene in both the control and the treatment groups at $24 \mathrm{~h}$ after $\mathrm{PH}$ (Figure 7). Although the increase of ras mRNA was slightly lower at $16 \mathrm{~h}$ after PH in CYC202-treated animals compared to DMSOtreated rats, the difference between these groups did not reach the level of statistical significance. Taken together, these data suggest that CYC202 does not significantly interfere with the examined key midG1 events of the cell cycle.

\section{Apoptosis is not Increased after CYC202 Administration}

Mortality rates 24 and $48 \mathrm{~h}$ after $\mathrm{PH}$ in animals treated with an inhibitory regimen of CYC202 reached 25 and $50 \%$, respectively. Since roscovitine 

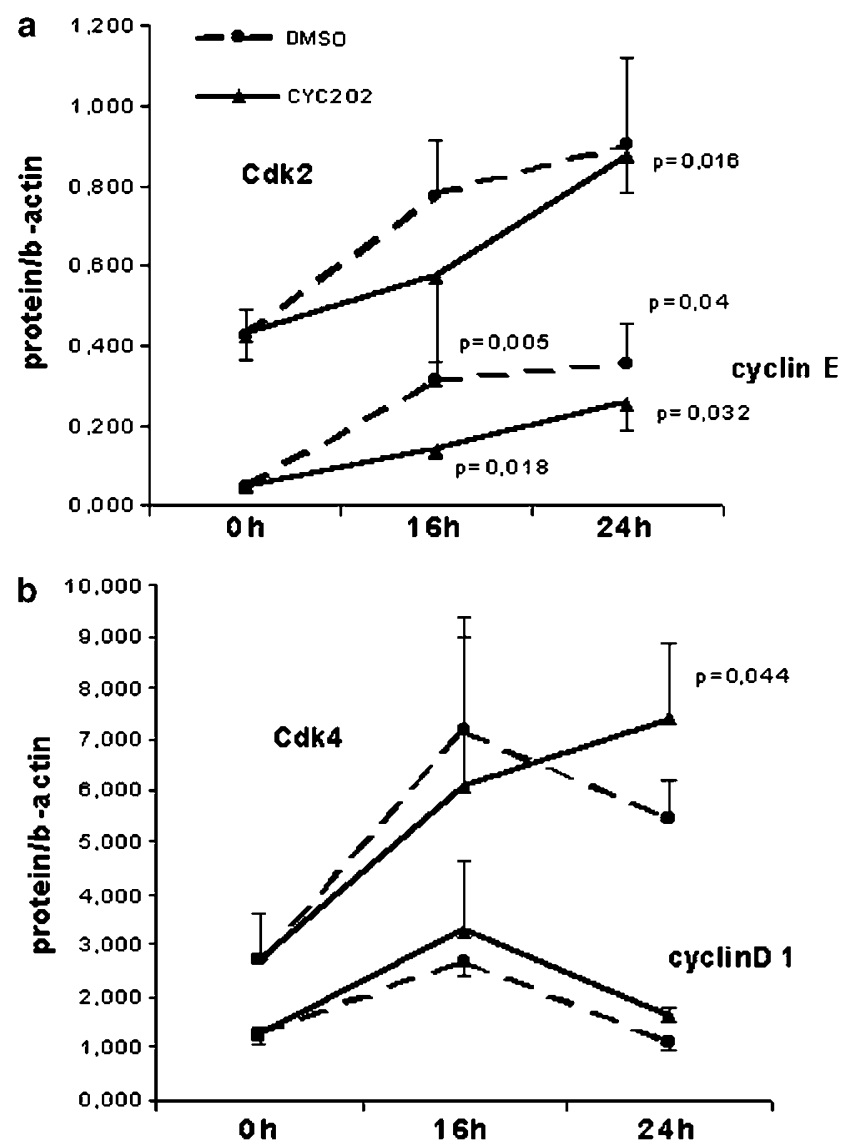

Figure 6 Densitometry analysis of cell cycle proteins in nuclear extracts normalized for loading controls $(\beta$-actin) before $(0 \mathrm{~h})$ and 16 and $24 \mathrm{~h}$ after partial hepatectomy $(\mathrm{PH})$ in DMSO-treated rats and in animals treated with an inhibitory regimen (two injections 8 and $20 \mathrm{~h}$ after $\mathrm{PH}$ ) of the Cdk2 inhibitor (CYC202, $75 \mathrm{mg} / \mathrm{kg}$ ). Means \pm s.e.m. are represented. Three to five animals per time point and per treatment group were analyzed. Similar protein expression for all investigated cell cycle proteins was observed at $24 \mathrm{~h}$ after $\mathrm{PH}$. The slight differences at $16 \mathrm{~h}$ after $\mathrm{PH}$ between the DMSO- and CYC202-treated animals were not statistically significant. The indicated $P$-values compare the DMSO or CYC202 groups to baseline levels before $\mathrm{PH}(0 \mathrm{~h})$.

has been reported to induce DNA fragmentation in vitro, ${ }^{27}$ we investigated whether increased apoptosis could contribute to the observed mortality rates. Careful examination of liver sections of CYC202treated animals did not reveal the presence of apoptotic bodies. Since histological signs of apoptosis occur late in the cascade of events that characterize the apoptotic process, we also assessed an earlier marker, that is, the caspase 3 activity, in these animals at 16, 24 and $48 \mathrm{~h}$ after PH. Surprisingly, there was a clear but statistically borderline trend $(P=0.07)$ towards reduced caspase 3 activity in CYC202-treated animals compared to their control (DMSO-treated) littermates at $24 \mathrm{~h}$ after $\mathrm{PH}$. If the CYC202-treated group at $16 \mathrm{~h}$ after $\mathrm{PH}$ was compared to the CYC202-treated group at $24 \mathrm{~h}$ after $\mathrm{PH}$, the reduction of caspase 3 activity observed in the latter one reached statistical significance $(P=0.031)$ (Figure 8). These results suggest that

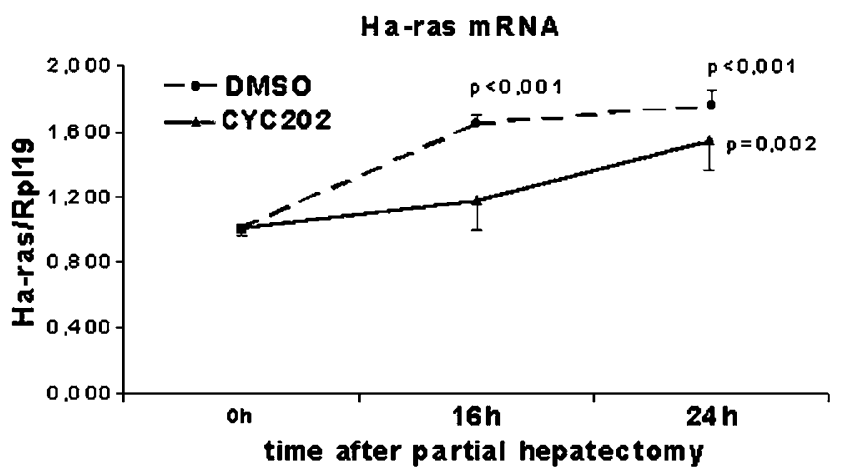

Figure 7 Expression of Ha-ras mRNA before $(0 \mathrm{~h})$ and 16 and $24 \mathrm{~h}$ after partial hepatectomy (PH) in different experimental groups. Means \pm s.e.m. are represented. Three to five animals per time point and per treatment group were analyzed. Low $\mathrm{C}$-Ha-ras expression was found before $\mathrm{PH}(0 \mathrm{~h})$. A similar and significant increase in $\mathrm{c}$-Ha-ras expression was observed in all experimental groups regardless whether or not the animals were injected DMSO only or received an inhibitory regimen of CYC202 $(75 \mathrm{mg} / \mathrm{kg}$; two injections 8 and $20 \mathrm{~h}$ after $\mathrm{PH})$. The indicated $P$-values compare basic expression $(0 \mathrm{~h})$ to levels obtained after $\mathrm{PH}$ in the experimental groups.

\section{Caspase 3 activity}

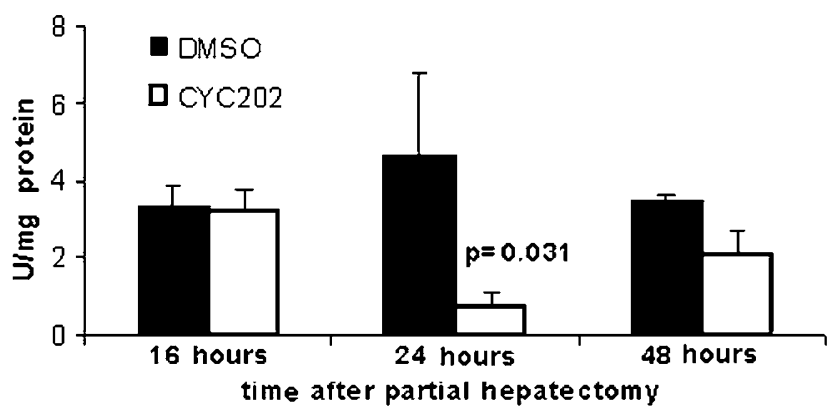

Figure 8 Caspase 3 activity in liver homogenates of DMSOtreated rats and animals treated with an inhibitory regimen of CYC202 after partial hepatectomy (PH). Means \pm s.e.m. are represented. Three to five animals per time point and per treatment group were analyzed. Caspase 3 activity 24 and $48 \mathrm{~h}$ after $\mathrm{PH}$ was lower in animals treated with two injections of CYC202 $(75 \mathrm{mg} / \mathrm{kg}) 8$ and $20 \mathrm{~h}$ after PH compared to their DMSOtreated littermates.

increased apoptosis does not account for the mortality observed in CYC202-treated animals in which Cdk2 activity is abrogated and, as a consequence, S-phase entry is profoundly disturbed.

\section{CYC202 Treatment does Neither Produce Kidney Nor Intestinal Alterations}

Since mortality rates in animals treated with Cdk2 inhibitory regimens of CYC202 were relatively high, we wanted to exclude potential toxic effects outside the liver that might be responsible for death. Hematoxylin-eosin-stained sections of the kidneys and the different parts of the intestine in animals 
treated with an Cdk2 inhibitory regimen were carefully examined by an experienced pathologist focusing on potential histological signs of toxicity. In the kidney, glomeruli and tubules were normally developed without signs of tubular necrosis or plug formation within the tubules suggestive of potential nephrotoxic effects of the substance (not shown). In the intestine, a constantly proliferating organ, villosities and crypts did not show any histological alterations. In addition, normal mitotic figures were observed in the intestinal crypts (not shown). These observations suggest the absence of intestinal toxicity at the investigated time points.

\section{Inhibition of Cdk2 Activity is Reversible and Reversibility is Associated with Cell Cycle Progression and Survival of the Animals}

We assessed whether inhibition of Cdk2 activity is maintained beyond the 24th hour in surviving animals treated with two injections at 8 and $20 \mathrm{~h}$ after PH. In control (DMSO-treated) animals, Cdk2 activity decreased at $48 \mathrm{~h}$. In the CYC202-treated animals, Cdk2 activity was high at $48 \mathrm{~h}$ after $\mathrm{PH}$ (Figure 9). This was associated with resumption of the cell cycle as indicated by a upregulation of PCNA expression (Figure 8), increased in BrdU incorporation (Figure $2 \mathrm{~b}$ ) and a rise in the mitotic index (Figure 3b) in CYC202-treated survivors. These findings suggest that Cdk2 inhibition by CYC202 is reversible and that the reversibility allows re-entry into the cell cycle and, likely, survival of the animals.

\section{Discussion}

Liver regeneration after partial hepatectomy constitutes an ideal model to study cell cycle events and

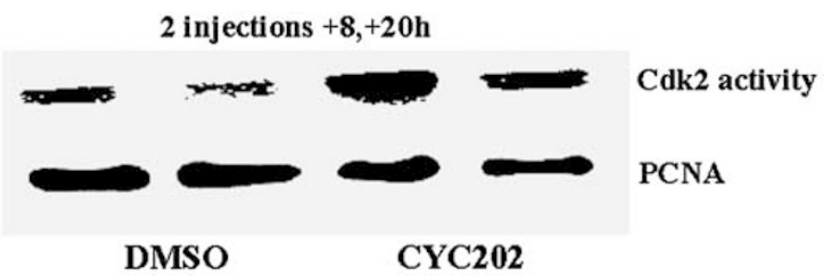

Figure 9 Cdk2 activity and PCNA protein expression in surviving animals $48 \mathrm{~h}$ after partial hepatectomy (PH). Nuclear extracts for Cdk2 activity and cell lysates for PCNA expression were prepared from surviving animals treated with DMSO or an inhibitory regimen (two injections $8 \mathrm{~h}$ and $20 \mathrm{~h}$ after $\mathrm{PH}$ ) of CYC202 (75 $\mathrm{mg} / \mathrm{kg}$ ). Blots were analyzed by densitometry and means \pm s.e.m. are given in brackets. Cdk2 activity started to decrease at $48 \mathrm{~h}$ after $\mathrm{PH}$ in DMSO-treated animals $(0.50 \pm 0.04, n=3)$, whereas a strong reactivation of Cdk2 activity occurred in animals that survived the CYC202 treatment for at least $48 \mathrm{~h}$ after $\mathrm{PH}(2.49 \pm 0.01$, $P<0.001, n=3)$. Reoccurrence of Cdk2 activity in CYC202-treated animals was associated with increased PCNA expression $(5.00 \pm 0.81)$ similar to those observed in the DMSO group (4.71 $\pm 0.77, P=$ not significant) suggesting that inhibition of Cdk2 may be reversed in surviving rats with subsequent restoration of cell cycle progression. their respective role in vivo. Cyclins and their kinase partners, the Cdks, play important roles in assuring a coordinated progression through the cell cycle. In particular, the active cyclin E/Cdk2 complex seems to allow progression from $\mathrm{G} 1$ to $\mathrm{S}$ phase of the cell cycle. $^{3-5}$ Several cyclins and Cdks are activated in the regenerating rat hepatocyte with the peak of DNA synthesis (S phase) occurring around the 24th hour after $\mathrm{PH}^{6,8,9}$ Although the activation of some cyclin/Cdk complexes, including cyclin E/Cdk2, might be more specifically associated with the regenerative process itself, ${ }^{10}$ there is no direct evidence to date that activation of cyclin E/Cdk2 plays a determinant role in orchestrating cell cycle progression in the regenerating liver. We therefore investigated the impact of targeted inhibition of Cdk2 kinase activity on proliferation of hepatocytes after partial hepatectomy in the rat. We used a new compound, the Cdk2 inhibitor CYC202, to test the consequences of inhibition of Cdk2 kinase activity on cell cycle progression after PH. CYC202 belongs to a group of compounds (purine analogues) also known as roscovitine that almost exclusively bind to Cdk2 blocking its kinase activity by masking the ATP-binding pocket. ${ }^{15-19}$ Our investigations provide direct evidence that late G1-S phase cell cycle progression was profoundly disturbed in the regenerating rat hepatocytes in vivo as a consequence of targeted inhibition of Cdk2. Administration of a high-dose regimen of CYC202 completely blocked Cdk2 activity $24 \mathrm{~h}$ after $\mathrm{PH}$ whereas low-dose CYC202 did not show any effect. S-phase entry and DNA synthesis assessed by two independent markers (PCNA expression and BrdU incorporation) was completely abrogated at the expected peak of DNA synthesis at $24 \mathrm{~h}$ after $\mathrm{PH}$. Inhibition of S-phase entry also translated into complete absence of mitotic figures in the treated animals which, by contrast, were already found in the control group $24 \mathrm{~h}$ after $\mathrm{PH}$. Mortality increased progressively from $25 \%$ at $24 \mathrm{~h}$ to $50 \%$ at $48 \mathrm{~h}$ after $\mathrm{PH}$ in animals treated with the Cdk2-inhibitory regimen of CYC202. Mortality could not be attributed to increased apoptosis since neither apoptotic bodies nor increased caspase 3 activity was found after CYC202 treatment. On the contrary, CYC202-treated animals showed a clear trend towards reduced caspase 3 activity. It is also very unlikely that the animals died as a consequence of a overall toxic effect of the molecule since the inhibitor has to be present during a narrow time frame corresponding to the G1/S phase transition of regenerating hepatocytes. Furthermore, consecutive injections before and up to $8 \mathrm{~h}$ after $\mathrm{PH}$ did not produce any mortality, in opposite to what one would expect in case of overall drug toxicity before or even after PH. Careful histological assessment of the kidney and the intestine in animals treated with an inhibitory regimen of CYC202 did not show any signs of drug toxicity in these organs. In addition, the proliferative activity with mitotic figures and normal crypt 
development was preserved in the intestine. These observations attest that, the regenerative capacity is preserved in an organ in which cell proliferation is not synchronized, in opposite to a tightly synchronized proliferation process in the liver after $\mathrm{PH}$. Taken together, it seems very unlikely that high mortality rates in CYC202-treated animals could be explained by toxic effects of the drug outside the liver. It is therefore opportune to postulate that death is closely related to the blockade of S-phase entry in regenerating hepatocytes and that only animals that were able to overcome this block ultimately survived the hepatectomy. Interestingly, the maximal cell cycle inhibitory effect was observed when the compound was administered between the 8th and the 20th hour after $\mathrm{PH}$, a time period that is thought to correlate with G1/S-phase transition in regenerating hepatocytes. ${ }^{24}$ The effect of CYC202 was completely lost when the treatment was stopped at the 8th hour after PH or when only a single injection was given at $20 \mathrm{~h}$ after $\mathrm{PH}$. Furthermore, additional injections before the 8th hour after $\mathrm{PH}$ do not seem to enhance the inhibitory effect of CYC202. These observations underline the importance of the cell cycle events occurring beyond the 8th hour after $\mathrm{PH}$ in the regenerating rat liver among which activation of Cdk2 seems to play a determinant role. Such a role is also consistent with the profile of Cdk2 activation in the regenerating rat hepatocytes, which is hardly detectable before the 14th hour and which peaks between the 20th and 24th hour after $\mathrm{PH}^{6,28}$ Abnormalities in expression and/or nuclear distribution of cyclin $\mathrm{E}$ and Cdk2 were found in most of the studies that reported disturbances in the regeneration process. ${ }^{11,13,29}$ In addition, it has recently been reported that targeted induction of cyclin $\mathrm{E}$ was sufficient to trigger cell cycle progression in quiescent hepatocytes. ${ }^{14}$ In our experiments, CYC202 did not affect cyclin E and Cdk2 upregulation nor their nuclear redistribution. This observation is consistent with data obtained in vitro where inhibition of Cdk2 activity occurred without changing the levels of cell cycle proteins. ${ }^{15}$ However, increased expression and nuclear translocation of cyclinE/Cdk2 complexes were not sufficient to push hepatocytes into $\mathrm{S}$ phase and DNA synthesis as long as Cdk2 activity was inhibited suggesting that stimulation of Cdk2 kinase activity remains an important step in this cascade of events. Our results are in accordance with the observation made by Wang et $a l^{30}{ }^{30}$ who reported that C-EBPalpha-induced growth arrest in hepatocytes was mediated through inhibition of Cdk2 activity. However, inhibition of Cdk2 in their experimental setting was due to the absence of cyclin E/Cdk2 complex formation. The inhibitor used in our studies directly targets the catalytic site of the kinase without affecting the formation of cyclinE/Cdk2 complexes providing therefore a more direct approach in evaluating the importance of this kinase in orchestrating the cell cycle.
The important role of Cdk2 activation for cell cycle progression is further sustained by the observation that an escape from Cdk2 inhibition seemed to be mandatory to allow subsequent resumption of the cell cycle and survival of the animals. These intriguing findings also suggest that the block of Cdk2 activity may be reversible under yet unknown conditions in animals that received two injections of CYC202 at 8 and $20 \mathrm{~h}$ after $\mathrm{PH}$. Elimination of the active compound and subsequent insufficient concentration to maintain the inhibitory effect might explain at least partly this phenomenon.

Roscovitine does principally affect Cdk2 activity but minor effects on cdc2 and cdk5 have also been suggested..$^{15}$ There is no absolute certainty that other important effectors of the cell cycle are not influenced by the molecule thereby contributing to the inhibition of cell cycle progression. We therefore investigated the expression and nuclear redistribution of cyclin D1 and Cdk4, both of which seem to be implicated in controlling the mid-G1 phase check point of the cell cycle, which is situated upstream of the check-point controlled by the cyclin E/Cdk2 complex in the regenerative process. ${ }^{6-8}$ Neither nuclear redistribution nor nuclear upregulations of both cyclin D1 and Cdk4 were altered by CYC202compared to DMSO-treated controls. This observation, in addition to normal upregulation and nuclear redistribution cyclin $\mathrm{E}$ and $\mathrm{Cdk} 2$, suggests that induction of the protein components of two important effector complexes of the cell cycle were not affected by the active compound. Therefore, and assuming that cell progression follows a cascade of events in which the previous step is required for the activation of the following one, it is opportune to postulate that mid to late G1-phase progression was not altered in the animals treated with the active compound. Furthermore, activation of ras has been shown to be required for G1 progression. ${ }^{31}$ The protooncogene increases in the regenerating rat liver and its inhibition interferes with cell cycle progression after $\mathrm{PH}$ in rats. ${ }^{13,32,33}$ In our experiments, ras increased similarly in the livers of both CYC202and DMSO-treated rats after PH. Ras might also provide a link between the cyclin $\mathrm{D} / \mathrm{Cdk} 4$ and the cyclin E/Cdk2 complex in cycling hepatocytes. ${ }^{34,35}$ Therefore, the observation of similar upregulation of ras in rats administered the active compound compared to controls constitutes an additional argument for normal early cell cycle progression underscoring that CYC202 specifically inhibits late G1-S-phase transition, blunting cell proliferation.

In conclusion, our studies underline the importance of the events occurring beyond the 8th but before the 24th hour after $\mathrm{PH}$ in rats for the liver regeneration to proceed normally. They identify Cdk2 as a key factor in orchestrating late G1-Sphase progression in the regenerating rat hepatocytes. Our results further suggest that reactivation of this kinase in surviving animals is required for 
regenerating hepatocytes to engage $S$ phase and, finally, to progress normally with their cell cycle.

\section{Acknowledgements}

The work was supported by grants from AstraZeneca, Belgium and from the FRSM (3.4532.99F).

\section{References}

1 Fausto N. Liver regeneration. J Hepatol 2000;32 (Suppl 1):19-31.

2 Mangall D, Bird NC, Majeed AW. The molecular physiology of liver regeneration following partial hepatectomy. Liver Int 2003;23:124-138.

3 Sherr CJ. G1 phase progression: cycling on cue. Cell 1994;79:551-555.

4 Sherr CJ, Roberts JM. CDK inhibitors: positive and negative regulators of G1-phase progression. Genes Dev 1999;13:1501-1512.

5 Coqueret O. Linking cyclins to transcriptional control. Gene 2002;299:35-55.

6 Jaumot M, Estanyol JM, Serratosa J, et al. Activation of $\mathrm{Cdk} 4$ and Cdk2 during rat liver regeneration is associated with intranuclear rearrangements of cyclin-Cdk complexes. Hepatology 1999;29:385-395.

7 Albrecht JH, Poon RYC, Ahonen CL, et al. Involvement of p21 and p27 in the regulation of CDK activity and cell cycle progression in the regenerating liver. Oncogene 1998;16:2141-2150.

8 Albrecht JH, Brenda MR, Nelsen CJ, et al. Regulation of G1 cyclin-dependent kinases in the liver: role of nuclear localization and p27 sequestration. Am J Physiol 1999;277:G1207-G1216.

9 Ehrenfried JA, Tien CK, Thompson EA, et al. Cell cycle-mediated regulation of hepatic regeneration. Surgery 1997;122:927-935.

10 Starkel P, Lambotte L, Sempoux C, et al. After portal branch ligation in the rat, cellular proliferation is associated with selective induction of c-Ha-ras, p53, cyclin E, and Cdk2. Gut 2001;49:119-130.

11 Vail ME, Chaisson ML, Thompson J, et al. Bcl-2 expression delays hepatocyte cell cycle progression during liver regeneration. Oncogene 2002;21:15481555.

12 Trautwein C, Will M, Kubicka S, et al. 2-Acetaminofluorene blocks cell cycle progression after hepatectomy by p21 induction and lack of cyclin E expression. Oncogene 1999;18:6443-6453.

13 Ludde T, Kubicka S, Plumpe J, et al. Ras adenoviruses modulate cyclin E protein expression and DNA synthesis after partial hepatectomy. Oncogene 2001; 20:5264-5278.

14 Nelsen CJ, Hansen LK, Rickheim DG, et al. Induction of hepatocyte proliferation and liver hyperplasia by the targeted expression of cyclin E and skp2. Oncogene 2001;20:1825-1831.

15 Meijer L, Borgne A, Mulner O, et al. Biochemical and cellular effects of roscovitine, a potent and selective inhibitor of cyclin-dependent kinases cdc2, cdk2 and cdk5. Eur J Biochem 1997;243:527-536.

16 Gray N, Detivaud L, Doerig C, et al. ATP-site directed inhibitors of cyclin-dependent kinases. Curr Med Chem 1999;6:859-875.
17 Noble MEM, Endicott JA, Johnson LN. Protein kinase inhibitors: insights into drug design from structure. Science 2004;303:1800-1805.

18 McClue SJ, Blake D, Clarke R, et al. In vitro and in vivo antitumor properties of the cyclin dependent kinase inhibitor CYC202 (R-roscovitine). Int J Cancer 2002; 102:463-468.

19 Higgins GM, Anderson RM. Experimental pathology of the liver. Arch Pathol 1931;12:186-202.

20 Starkel P, Bishop K, Horsmans Y, et al. Expression and DNA-binding activity of signal transducer and activator of transcription 3 in alcoholic cirrhosis compared to normal liver and primary biliary cirrhosis in humans. Am J Pathol 2003;162:587-596.

21 Picard C, Lambotte L, Starkel P, et al. Steatosis is not sufficient to cause an impaired regenerative response after partial hepatectomy in rats. J Hepatol 2002;36:645-652.

22 Borbath I, Gregoire V, Bergstrom M, et al. Use of 5[(76)Br]bromo-2' -fluoro-2'-deoxyuridine as a ligand for tumour proliferation: validation in an animal tumour model. Eur J Nucl Med Mol Imaging 2002;29:19-27.

23 Picard C, Starkel P, Sempoux C, et al. Molecular mechanisms of apoptosis in the liver of rats after portal branch ligation with and without retrorsine. Lab Invest 2004;84:618-628.

24 Loyer P, Cariou S, Glaise D, et al. Growth factor dependence of progression through G1 and S phase of adult rat hepatocytes in vitro. J Biol Chem 1996;271: 11484-11492.

25 Krude T, Jackman M, Pines J, et al. Cyclin/Cdkdependent initiation of DNA replication in a human cell-free system. Cell 1997;88:109-119.

26 Krude T. Initiation of human DNA replication in vitro using nuclei from cells arrested at an initiationcompetent state. J Biol Chem 2000;275:13699-13707.

27 N'cho M, Brahmi Z. Evidence that Fas-induced apoptosis leads to S phase arrest. Hum Immunol 2001; 62:310-319.

28 Pujol MJ, Jaime M, Serratosa J, et al. Differential association of p21Cip1 and p27Kip1 with cyclin E-CDK2 during rat liver regeneration. J Hepatol 2000;33:266-274.

29 Wustefeld T, Rakemann T, Kubicka S, et al. Hyperstimulation with interleukin 6 inhibits cell cycle progression after hepatectomy in mice. Hepatology 2000;32:514-522.

30 Wang $\mathrm{H}$, Iakova $\mathrm{P}$, Wilde $\mathrm{M}$, et al. C/EBPalpha arrests cell proliferation through direct inhibition of Cdk2 and Cdk4. Mol Cell 2001;8:817-828.

31 Takuwa N, Takuwa Y. Regulation of cell cycle molecules by the Ras effector system. Mol Cell Endocrinol 2001;177:25-33.

32 Goyette M, Petropoulos CJ, Shank PR, et al. Regulated transcription of c-Ki-ras and c-myc during compensatory growth of rat liver. Mol Cell Biol 1984;4:1493-1498

33 Thompson NL, Mead JE, Braun L, et al. Sequential protooncogene expression during rat liver regeneration. Cancer Res 1986;46:3111-3117.

34 Auer KL, Park JS, Seth P, et al. Prolonged activation of the mitogen-activated protein kinase pathway promotes DNA synthesis in primary hepatocytes from p21Cip-1/ WAF1-null mice, but not in hepatocytes from p16INK4anull mice. Biochem J 1998;336:551-560.

35 Wheeler MD, Smutney OM, Check JF, et al. Impaired Ras membrane association and activation in PPAR $\alpha$ knockout mice after partial hepatectomy. Am J Physiol Gastrointest Liver Physiol 2003;284:G302-G312. 